handled by women colleagues in the team, particularly in occupational health and safety.

\section{7e PREDOMINANCE OF MUSCULOSKELETAL AILMENTS AND ALLIED WORK-RELATED CONTRIBUTING FACTORS AMONGST CONSTRUCTION LABOURERS OF WEST BENGAL, INDIA}

Arijit Chatterjee, Koumi Dutta, Subhashis Sahu. Ergonomics and Occupational Physiology Laboratory, Department of Physiology, University of Kalyani, Kalyani, India

\subsection{6/oemed-2018-ICOHabstracts.232}

Introduction An enormous number of labourers engaged in construction industry in India both in organised and unorganised sectors. The construction labourers regularly work for a broadened time frame and they are compiled to maintain adjusted static and dynamic working positions in unbalanced locations during the total time of work which raises the demand of the musculoskeletal system and may lead to work related musculoskeletal ailments.

Objective This study is proposed to investigate the operational position and work related musculoskeletal ailments among the construction workers. One eighty four male workers from various construction sites of West Bengal was indiscriminately taken for this study.

Methods A modified Nordic questionnaire on MSD and the 12 item General Health Questionnaire (GHQ12) were administered on the construction labourers. REBA and OWAS posture analysis techniques were applied to evaluate the awkward postures. At last, discomfort levels of the particular working positions were figured by the use of risk level and BPD scale. Results From the study it was uncovered that the greater part of the construction labourers frequently in unbalanced and awkward working position and were allied by different workrelated contributing factors like pain in low back, neck, and wrist. It has been likewise discovered that there is a significant $(\mathrm{p}<0.05)$ association between the intensity of pain feeling, age, year of working experience and risk level of the individual working postures of the labourers.

Conclusion Suitable work-rest schedule, revisions of some working techniques and use of some ergonomically modified tools may decrease the WMSDs and enhance the health eminence and wellbeing distinction of construction labourers in unorganised sectors.

\section{PARTICIPATORY APPROACH IMPROVING SAFETY AND HEALTH IN CONSTRUCTION INDUSTRY}

Henk F van der Molen*. Academic Medical Center, University of Amsterdam, Department Coronel Institute of Occupational Health, Amsterdam Public Health research institute, Amsterdam, The Netherlands

10.1136/oemed-2018-ICOHabstracts.233

Aim of special session Utility and feasibility of participatory approaches to increase health and safety measures at (construction) worksites.

${ }^{1}$ Maaike Huysmans PhD, ${ }^{2}$ Jack Dennerlein $\mathrm{PhD},{ }^{3}$ Dwayne van Eerd PhD, ${ }^{4}$ Ann Marie Dale PhD, ${ }^{5}$ Henk F van der Molen $\mathrm{PhD}$

${ }^{1}$ Department of Public and Occupational Health, VU University Medical Center, Amsterdam, The Netherlands
${ }^{2}$ Bouvé College of Health Sciences, Northeastern University, Boston MA, USA

${ }^{3}$ Institute for Work \& Health, Toronto, Canada

${ }^{4}$ Division of General Medical Sciences, Washington University School of Medicine in St. Louis, St. Louis, MO, USA

${ }^{5}$ Academic Medical Center, University of Amsterdam, Department: Coronel Institute of Occupational Health, Amsterdam Public Health research institute, Amsterdam, The Netherlands

\section{7a DEVELOPMENT OF A GUIDELINE 'PARTICIPATORY APPROACH AT THE WORKPLACE' IN THE NETHERLANDS}

1,2,3 Maaike Huysmans * 1,2,3 Frederieke Schaafsma, ${ }^{1,2,3}$ Han Anema. ${ }^{1}$ Department of Public and Occupational Health, VU University Medical Centre, Amsterdam, The Netherlands; ${ }^{2}$ Amsterdam Public Health research institute, Amsterdam, The Netherlands; ${ }^{3}$ Research Centre for Insurance Medicine, AMC-UMCG-UWV-VUmc, Amsterdam, The Netherlands

\subsection{6/oemed-2018-ICOHabstracts. 234}

Introduction In the Netherlands, we aimed to develop a multidisciplinary guideline for the Participatory Approach (PA) at the Workplace, in collaboration with insurance physicians, work experts, occupational health physicians, occupational health nurses, occupational hygienists, and occupational therapists.

Methods A working group of representatives from all 7 participating professions defined the topics that needed to be addressed by the guideline. When possible the guideline was based on scientific evidence. In case of none or insufficient scientific evidence, the working group formulated an expert opinion. After incorporating feedback from experts in the field the concept guideline was finalised. This whole process was supervised by a steering committee.

Results In the guideline, PA was defined as a systematic approach consisting of six predefined steps in which worker(s) and relevant stakeholders (e.g. supervisors or employer) reach consensus on the main problems and solutions for the worker (s)'s health problems and work participation. This results in an action plan defining who does what and when. One should start (step 1) with creating the right conditions and end with a proper evaluation of the pre-set goals (step 6). The guideline can be used to apply the PA at an organisational (mainly primary prevention and targeting groups of workers) or an individual level (treatment and re-integration of the individual worker). Our systematic literature review showed that the PA at an organisational level was effective for improving (determinants of) behaviour, reducing musculoskeletal symptoms, improving work performance, reducing sick leave and reducing costs. At the individual level the PA appeared especially effective to reduce sick leave and fasten return-to-work.

Discussion We successfully developed an evidence-based multidisciplinary guideline for the Participatory Approach at the Workplace. Currently, we face the challenge of successfully implementing the guideline in practice by arranging authorisation among the professional groups and giving trainings in the field.

\section{7b IMPROVING EMPLOYEE INVOLVEMENT THROUGH SAFETY COMMUNICATION}

${ }^{1}$ Jack T Dennerlein*, ${ }^{2}$ Emily H Sparer. ${ }^{1}$ Bouvé College of Health Sciences, Northeastern University, Boston, MA USA; ${ }^{2}$ Harvard T.H. Chan School of Public Health, Boston, MA, USA

10.1136/oemed-2018-ICOHabstracts.235 
Introduction Employee safety incentive programs are a form of communicating to engage employees to increase the use of safety controls ranging from the use of proper tools, pre-task planning, to the use of personal protective equipment. We developed a safety communication and recognition program designed to encourage improvement of physical working conditions and hazard reduction in construction. The program communicated how well both the work site and individual subcontractors were controlling hazards on the site.

Methods To evaluate the developed program, we completed a cluster randomised controlled trial on eight worksites for approximately five months per site. Pre- and post- worker surveys measured changes in safety climate $(n=615$ with follow up rate of $88 \%$ ). Multi-level mixed effect regression models tested the effect of B-SAFE on safety climate as assessed from surveys. Focus groups $(\mathrm{n}=6-8$ workers/site) provided qualitative measures of changes not measured via the surveys.

Result Safety climate score at intervention sites improved. The intervention effect size was $1.64(3.28 \%)$ (P-value=0.01) when adjusted for month the worker started on-site, total length of time on-site, as well as individual characteristics (trade, title, age, and race/ethnicity). At intervention sites, workers noted increased levels of safety awareness, communication, and teamwork compared to control sites. Managers noted that subcontractors worked together and workers were engaged in the communication and receiving the data.

Discussion The program led to many positive changes, including an improvement in safety climate, awareness, teambuilding, and communication. The program is a simple approach to engaged workers through effective communication infrastructures and had a significant, positive effect on worksite safety

\section{C SHARING SOLUTIONS IN PARTICIPATORY ERGONOMICS - A KEY TO SUSTAINABILITY}

1,2D Van Eerd*, 'T D'Elia, 'EM Ferron, ${ }^{1,3}$ B Amick. 'Institute for Work and Health, Toronto, Canada; ${ }^{2}$ University of Waterloo, Waterloo, Canada; ${ }^{3}$ Florida International University, Miami, USA

\subsection{6/oemed-2018-ICOHabstracts.236}

Introduction Musculoskeletal disorders (MSD) and slips, trips, and falls (STF) are a major source of workplace injuries. In Ontario, MSD account for upwards of $40 \%$ and STF account for almost $20 \%$ of all lost-time claims depending on sector. Our objective was to integrate stakeholder perspectives about the implementation of a participatory ergonomics program.

Methods The project builds on a recently completed pilot study and process evaluation of the Employee Participation in Change (EPIC) program in three work sites (391 workers) within one organisation. Individual interviews were conducted with Program Champions $(n=3)$ and an interactive stakeholder workshop, including a moderated focus group $(n=13)$, was held. Data from Program Champions informed the interactive workshop. Focus group data centred on strategies for knowledge sharing and program recommendations. Transcripts and field notes were analysed for emerging themes.

Results Participants reported positive experiences with program implementation. EPIC has been sustained and incorporated into existing health and safety procedures at all sites. Improvements in communication about safety were noted in all cases. Funding to implement changes remains a challenge in all sites.

Program champions, site administrators and worker representatives led discussions consistently noted positive changes but also described the need for iteration in solution development. Focus group results included suggestions to reduce program training and paperwork burdens. Key barriers included the time it takes to implement solutions.

Frontline workers continue to use EPIC hazard identification tools and practices, and communicate about hazards and solutions regularly. The 'raised awareness' from EPIC has persisted. A key facilitator to success included the role of ergonomics consultants.

Conclusion EPIC program stakeholders participated in an interactive workshop to inform improvements in program delivery and evaluation of a participatory intervention. Participants noted that sharing solutions across sites would have been useful earlier. Future implementation research will incorporate solution sharing opportunities.

\section{7d PARTICIPATORY ERGONOMIC PROGRAMS IN COMMERCIAL CONSTRUCTION PROJECTS: ENGAGEMENT WITH MULTIPLE ORGANISATIONAL LEVELS TO IMPROVE EFFECTIVENESS}

${ }^{1}$ AM Dale*, ${ }^{2}$ L Welch, ${ }^{1}$ BA Evanoff. 'Division of General Medical Sciences, Washington University School of Medicine in St. Louis, St. Louis, MO, USA; ${ }^{2}$ CPWR-The Centre for Construction Research and Training, Silver Springs, MD, USA

\subsection{6/oemed-2018-ICOHabstracts.237}

Introduction Effective participatory ergonomic programs require cooperative engagement of management and workers to identify hazardous tasks and implement useful solutions. We report findings from participatory programs within seven single employers on different multi-employer construction projects.

Methods We trained all employees in ergonomic principles, hazard recognition, and use of a participatory approach to identify and implement feasible solutions. We measured program delivery and effectiveness through training records, number of identified hazardous tasks and solutions, and number of employer-controlled and worker-controlled solutions implemented over a three-month period.

Result Most (91\%) of the 95 workers were trained; participating workers identified 105 hazardous tasks. Equipment solutions for 43 of these tasks were the responsibility of the employer; workers were responsible for 44 tool and 8 work practice solutions. Ten hazardous tasks without solutions related to the construction environment and/or schedule that were controlled by the primary contractor. Relatively few employer-controlled equipment solutions (33\%) were implemented during the project while $75 \%$ of the worker-controlled tool solutions were implemented.

Discussion These results highlight two barriers to implementing effective solutions in single employer participatory ergonomic programs:

- employers do not involve workers in selecting useful equipment for projects, and

- primary contractors control the project schedule and environment.

The complex organisation of multi-employer sites and frequently changing work tasks and environments may account for the varied effectiveness of participatory ergonomic programs in construction. Most programs have engaged workers within single employers, rather than being integrated within 